Journal of Science
http://dergipark.gov.tr/gujs

\title{
Design of Epoxy Modified Recycled Rubber-Based Composites: Effects of Different Contents of Nano-Silica, Alumina and Graphene Nanoplatelets Modification on the Toughening Behavior
}

\author{
Alaeddin Burak IREZ ${ }^{1 *(1)}$, Emin BAYRAKTAR ${ }^{2}$ (D) \\ ${ }^{1}$ Université Paris-Saclay, ENS Paris-Saclay, CNRS, LMT - Laboratoire de Mécanique et Technologie, 94235, 7 Cachan, France \\ ${ }^{2}$ SUPMECA-Paris, School of Mechanical and Manufacturing Engineering, France
}

\author{
Highlights \\ - Surface activation of the recycled rubbers by microwaves improves the adhesion with the matrix \\ - Increasing content of the reinforcements improved elasticity modulus of the composites. \\ - The main toughening mechanisms in these composites were identified as crack pinning and crack deflection. \\ - Surface integrity of the composites were protected against to the wear. \\ - Fracture toughness and strain at break were degraded by the excessive amount of graphene.
}

Article Info

Received: 01/07/2019

Accepted: 11/09/2019

\section{Keywords}

Fracture toughness

Recycled rubber

Wear resistance

Damage mechanisms

\begin{abstract}
Multifunctional composite materials are recently drawing attention in many field including automotive, aeronautic and transport. The primary goal of this work is to propose low-cost and lightweight material for the automotive industry. In this study, recycled rubber-based composites were developed by using low cost manufacturing methods. At the beginning, recycled rubbers were devulcanized by microwaves to improve the bounding quality with the epoxy. Then, fine particles of recycled rubbers and solid epoxy were mixed together. After incorporating and rigorously distributing various contents of graphene nanoplatelets ( $\mathrm{GnPs})$, silica and $\gamma$-alumina particles in the matrix, hot compaction was used to manufacture the composites. As the second objective of this study, effect of reinforcement 5-10-15 wt. \% of silica, and various contents of $\mathrm{GnPs}$ and $\gamma$-alumina particles on toughening was examined. In this regard, notched specimens were used to determine critical stress intensity factor and critical strain energy release rate. Fracture toughness showed some fluctuations by the incremental quantity of the reinforcements. Moreover, flexural strength and elasticity modulus were calculated by means of bending tests (three-point, 3PB). Positive effects of reinforcements on elasticity modulus were observed by 3PB tests. In addition, Charpy impact tests were done to assess energy absorbing capacity of the composites. To check the dispersion quality and to identify toughening mechanisms, scanning electronic microscopy was used. The main toughening mechanisms in these composites were identified as crack pinning, crack deflection shear band formation as well as. Finally, wear resistance of the specimens was assessed by macro-scratch tests.
\end{abstract}

\section{INTRODUCTION}

Recycling is a topic addressing profound study for the point of sustainable development. Recycling is largely subsidized by the governments in many areas due to the international environmental agreements. For instance, manufacturers in many industries are looking to find cost-effective and sustainable alternatives by using recycled materials to produce new components. From this perspective, rubbers suggests very wide areas of use in the aeronautical and automotive industries such as structural components and parts of the interior body. Within this respect, the recycled clean rubber with the presence of efficient binders and inorganic inclusions will generate some of these elements. Owing to its convenience in processing, large specific stiffness and strength, environmental stability and inexpensiveness, epoxy is thought to be a pertinent thermosetting polymer as binder. [1]. In regards to inorganic reinforcements, 
alumina $\left(\mathrm{Al}_{2} \mathrm{O}_{3}\right)$ has decent mechanical properties, thermal stability and good wettability properties with epoxy resin. Besides, it is nontoxic and inexpensive [2,3]. As another inclusion, nano graphene has unique properties as a result of its 2-D honeycomb structure which makes it a promising nanoscale inclusion for polymer nanocomposites. It has an outstanding mechanical strength (130 GPa) and specific elasticity modulus (1 TPa) [4-6].Besides, high surface area of the nano fillers can improve the properties of the composites even at very low contents compared to the microscale fillers [7-9]. Lastly, silica mostly promote better materials properties of the incorporated polymers including resin stiffness [10] fracture toughness $[11,12]$ and wear resistance [13]. An optimum combination of the advantageous properties of the recycled rubbers, epoxy resin and the reinforcements makes possible to manufacture sustainable and cost-effective composite materials for the diverse functions in automotive and aeronautics.

Another important point is that in this study only fresh scrap rubber was used which is totally different from the ground tire rubber (GTR). In this project, in the manufacturing line of rubber-based objects (i.e shoe soles, sportive equipment) after cutting the required shape from the sheet rubber, our industrial partner collects directly unused parts from the line and these unused parts are sent to grinder to obtain fresh clean crumb rubber. Their main differences from GTRs, they do not contain any metallic inclusions or fibers. Because of the presence of metals, waste rubber can oxidize and overheat easily and this can cause to autoignition. Also, the inclusions may weaken the bonding quality with the blended material. In addition, scrap rubbers used in this study were not exposed to any stresses, as in the example of ground tire rubbers (GTR), which makes them more attractive compared to GTR. Besides, recycled rubbers are generally used to manufacture low cost composite manufacturing such as artificial sport surfacing, noise and vibration pads. However, in this study final composites are planned to be used in more advanced applications. These points constitute the novelty of this study.

This study introduces a cost-effective method to process recycled-rubber particles with epoxy resin and this blend was reinforced with graphene nanoplatelets (GnPs), alumina and nano silica. Determination of the mechanical properties and identification of toughening mechanisms of these composites constitutes the principal objective of this research. Also, impact behavior was examined with the help of Charpy impact tests. Then, composites' wear resistance were investigated by macro scratch tests. Finally, the toughening and damage mechanisms were identified by observing the fracture surfaces by means of SEM.

\section{EXPERIMENTAL PROCEDURE}

\subsection{Materials Processing}

Recycled rubber particles have some chemical incompatibilities with epoxy resin and this situation leads to poor interfacial properties [14]. Therefore, recycled rubber devulcanization is considered an important process to enhance the interface characteristics of epoxy with rubbers. By devulcanization, flowing capacity of the recycled rubbers is improved and also binding properties of rubbers with epoxy is enhanced to create robust composites.

During devulcanization, the structure of the material is entirely changed by breaking sulphur links (C-S) between carbon atoms and also some new other links are created. Manufacturing process of the composites is summarized below and more details can be found in our previous paper [14]:

First, recycled rubbers were chemically treated. During this chemical treatment, rubbers were exposed to small amount of toluene solution and acrylic acid for the surface activation of recycled rubbers $[15,16]$. Then, chemically treated rubbers were dried in the oven.

1- Following chemical treatment, recycled rubber is subjected to microwaves for 4 minutes and during this period magnetron power of the microwaves was selected as $900 \mathrm{~W}$.

2- Then, Vinyltrimethoxysilane 98\%, Sigma-Aldrich was used for silanization for the sake of adhesion enhancement of rubbers with epoxy.

3- When the preparation of the rubbers was terminated, epoxy resin powders were mixed with rubbers. This blend was then used as the matrix. From this step, powder metallurgy methods were used to complete the manufacturing of the novel composites. 
4- In this study, $\gamma$-alumina, GnPs and nano silica were used as reinforcing agents and they were mixed with the matrix by using a toothed-wheel mill during 4 hours to homogenize the microstructure and to decrease the size of rubber particles. Better granulometric distribution results in higher bonding on the contact surfaces. Thereby, mechanical stresses are well compensated. Also, milling can break the former bonds and it contributes to the partial devulcanization $[17,18]$.

5- Following obtaining a homogeneous compound, the manufacturing of the composites was carried out by hot compaction at $180^{\circ} \mathrm{C}$ under $70 \mathrm{MPa}$ of pressure. During this hot compaction, compression pressure generates the intimate contact between recycled rubber particles, and the energy to break the polysulfidic crosslinks is granted by the elevated temperatures. Free links from this step could create new bonds, which would enable the recycled rubber particles to generate a bulk material $[19,20]$.

6- After hot compaction, post-cure on the specimens were maintained isothermally at $80^{\circ} \mathrm{C}$ for 24 hours.

In Table 1, the compositions of manufactured composites are given in detail. Hereafter, these composites are named as SAG I - II - III.

Table 1. Composition of the manufactured composites

\begin{tabular}{|c|c|c|c|}
\hline $\begin{array}{c}\text { Epoxy - SBR rubber } \\
(10 \% \text { Epoxy - 90\% Rubber) }\end{array}$ & SAG I & SAG II & SAG III \\
\hline & 5 nano $\mathrm{SiO}_{2}$ & 10 nano $\mathrm{SiO}_{2}$ & 15 nano $\mathrm{SiO}_{2}$ \\
Reinforcements (wt. \%) & $2 \gamma-\mathrm{Al}_{2} \mathrm{O}_{3}$ & $4 \gamma-\mathrm{Al}_{2} \mathrm{O}_{3}$ & $6 \gamma-\mathrm{Al}_{2} \mathrm{O}_{3}$ \\
& $2 \mathrm{GnP}$ & $4 \mathrm{GnP}$ & $6 \mathrm{GnP}$ \\
\hline
\end{tabular}

In Figure 1, the specimens manufactured by hot compaction are shown as well as the powder to manufacture these composites is indicated in the upper left of Figure.1. The beam type specimen seen in bottom left corner was obtained by cutting circular specimens $(50 \mathrm{~mm})$.

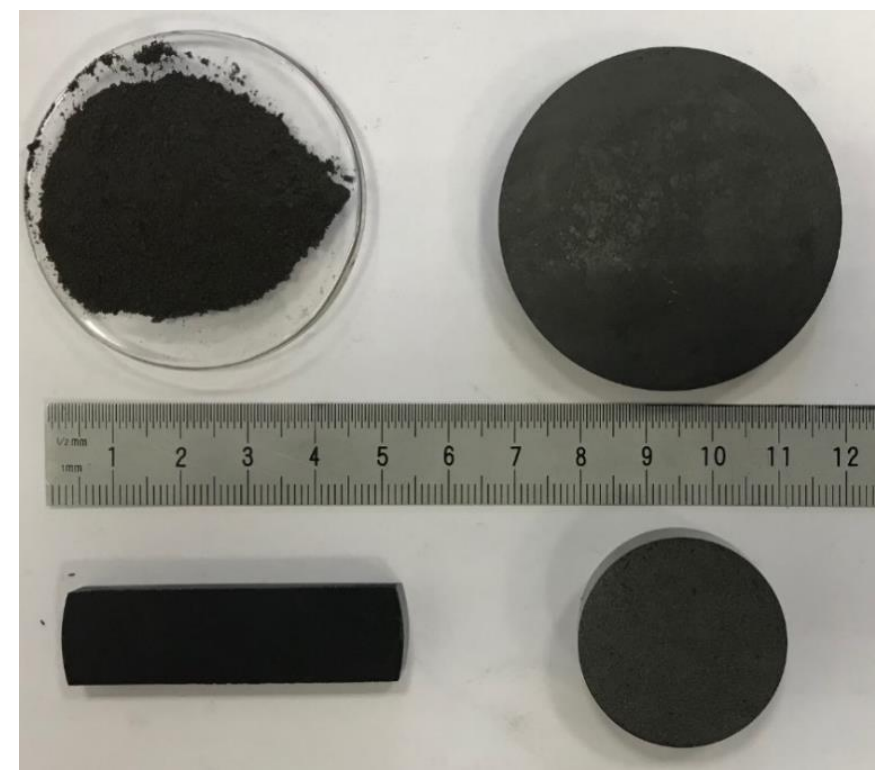

Figure 1. Specimens after completing manufacturing step

\subsection{Experimental Methods}

An optic microscope (OM) and Jeol ${ }^{\circledR}$ JSM-6010 scanning electron microscope were used for microstructural observations and the fractography. Sauter Shore D hardness tester was used for hardness measurement and five measurements were taken from different points on the surface. Zwick Proline Z050TN testing system was used for three - point bending tests by using five specimens for each 
composition and by taking into account ASTM D790, and crosshead speed was $1 \mathrm{~mm} / \mathrm{min}$. Furthermore, fractural toughness characteristics including critical strain energy release rate $\left(G_{I c}\right)$ and plain strain fracture toughness $\left(K_{I c}\right)$ were examined with SENB (single edge notched beam) specimens according to ASTM D5045. Zwick 5102 pendulum impact tester was used for Charpy impact tests.

The densities of the compositions were measured and for each composition, five different measurements were performed. Table 2 presents the results of the density measurements. According to Table 2 it is perceptible that increasing content of the reinforcements also increases the density of the composites. This is associated to the higher densities of the reinforcements compared to rubber and epoxy.

Table 2. Densities of SAG group composites

\begin{tabular}{|c|c|}
\hline Specimen & Density $\left(\mathbf{g} / \mathbf{c m}^{\mathbf{3}}\right)$ \\
\hline SAG I & $1,42 \pm 0,03$ \\
\hline SAG II & $1,43 \pm 0,07$ \\
\hline SAG III & $1,45 \pm 0,10$ \\
\hline
\end{tabular}

In this study, by performing macro scratch tests, fundamental idea on the tribological characteristics of these novel manufactured composites was assessed. During the tests, a damage trace was created under dry conditions by using a sliding diamond indenter for 50k and 100k cycles. After the test, to assess damaged zone an optical profilometer was used which gives the average scratch roughness and scratch depth on the damaged area.

\section{RESULTS AND DISCUSSIONS}

\subsection{Microstructural Observation and Surface Hardness of the Composites}

In Table 3, surface hardness of the composites is given. In composite design, hardness can be thought as an important parameter to define the potential applications for the manufactured composites.

Table 3. Shore D surface hardness of the manufactured composites

\begin{tabular}{|c|c|}
\hline \multicolumn{2}{|c|}{ Hardness Measurement } \\
\hline Specimen & Shore D \\
\hline SAG I & $77,0 \pm 0,2$ \\
\hline SAG II & $78,9 \pm 0,4$ \\
\hline SAG III & $79,5 \pm 0,9$ \\
\hline
\end{tabular}

It can be noticed that the surface hardness of the composite was increased by the increasing reinforcement content. However, there was not any hardness chance once reinforcement contents were increased further to $18 \mathrm{wt}$. \%. The increase in the standard deviations could be associated with the rise in heterogeneity of the composites by the increasing mass fraction of the inclusions.

The microstructure SAG II group is given in Figure 2 to represent the manufactured composites. It seems that a good interfacial cohesion between the matrix and reinforcements was obtained. There are no micro cracks between the hard and soft particles. Mainly, it is observed that rubber adhesion to the epoxy resin was well provided and it is attributed to the chemical treatment and devulcanization. White spherical particles in Figure 2 were found as $\gamma-\mathrm{Al}_{2} \mathrm{O}_{3}$ particles and black background is indicating the rubber particles surrounded by epoxy matrix seen in gray parts. 


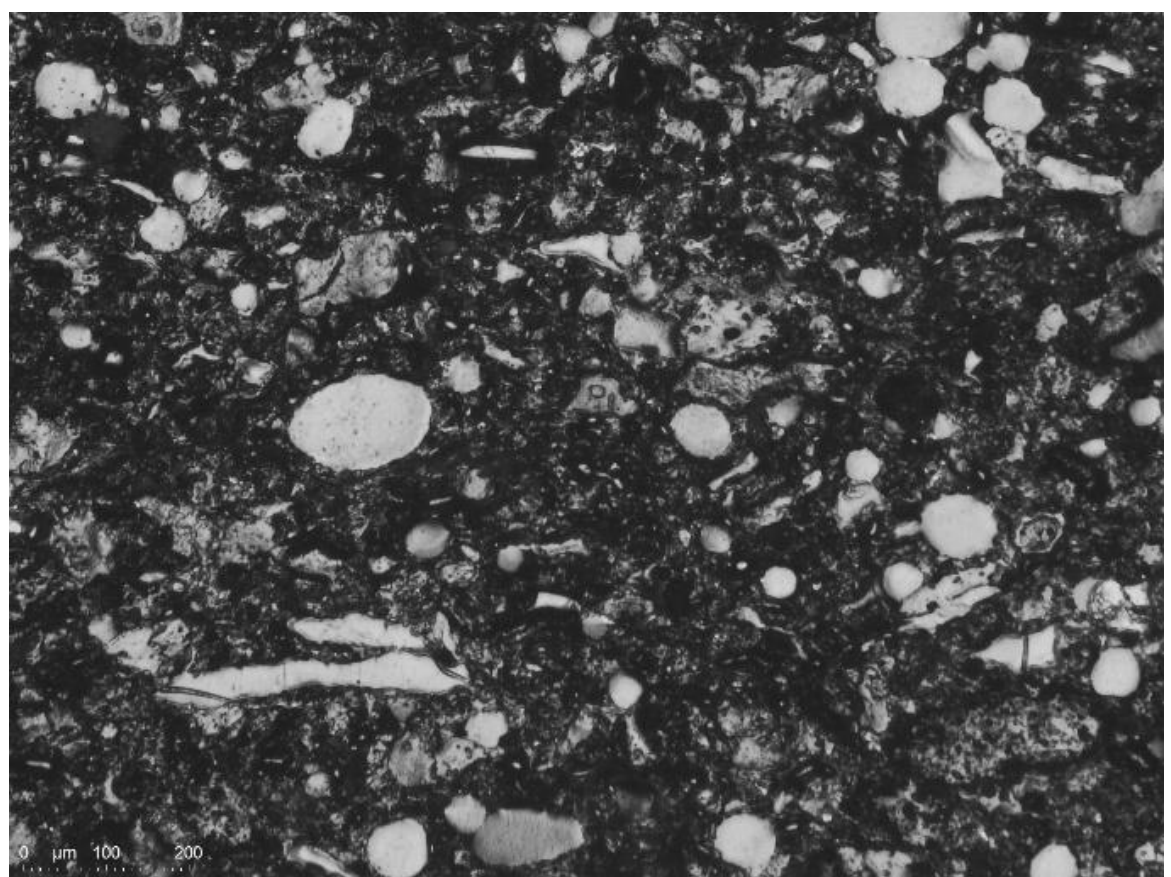

Figure 2. Microstructure of SAG II group composition after sectioning

\subsection{Mechanical Characterization}

Bending test is found more practical for the beam type specimens after hot compacting of these composites. Therefore, fundamental mechanical properties of the manufactured composites were determined by 3PB tests. In Table 4, results of the bending tests are presented. Ultimate flexural strength, flexural modulus and strain at failure were obtained by smooth rectangular specimens. However, fracture toughness values were determined by using SENB notched specimens.

Table 4. 3PB tests results on SAG group composites

\begin{tabular}{|c|c|c|c|c|c|}
\hline $\begin{array}{c}\text { Composition } \\
\text { name }\end{array}$ & $\begin{array}{c}\text { Ultimate } \\
\text { Flexural } \\
\text { Strength (MPa) }\end{array}$ & $\begin{array}{l}\text { Flexural } \\
\text { Modulus } \\
\text { (MPa) }\end{array}$ & $\begin{array}{c}\text { Strain at } \\
\text { break }(\varepsilon \%)\end{array}$ & $\begin{array}{c}\mathbf{K}_{\mathrm{Ic}} \\
\left(\mathrm{MPa} \mathrm{m}^{1 / 2}\right)\end{array}$ & $\underset{\left(\mathbf{k J} / \mathbf{m}^{2}\right)}{\mathbf{G}_{\mathrm{Ic}}}$ \\
\hline SAG I & $9,37 \pm 5,62$ & $3,34 \pm 0,47$ & $0,66 \pm 0,38$ & $0,61 \pm 0,004$ & $0,11 \pm 0,001$ \\
\hline SAG II & $14,42 \pm 2,63$ & $3,64 \pm 1,00$ & $0,42 \pm 0,03$ & $0,60 \pm 0,042$ & $0,10 \pm 0,013$ \\
\hline SAG III & $12,65 \pm 2,71$ & $3,70 \pm 0,74$ & $0,37 \pm 0,02$ & $0,67 \pm 0,076$ & $0,12 \pm 0,028$ \\
\hline
\end{tabular}

The first deduction from Table 4 is that ascending content of reinforcements resulted in an increase on the composite strength. This trend is attributed to the robust nature of the reinforcements added. In particular, elasticity modulus in bending was improved which is related to high moduli of the reinforcements. On the other hand, incorporation of excessive amount of the reinforcements brings a reduced strain at break to these composites. This result is associated to size related characteristics of the reinforcements. First, because of graphene synthesis process, graphene sheets have a natural tendency to the agglomeration due to the interlaminar van der Waals forces. Moreover, the strong attractive interaction between fine particles and high total surface area of the nano particles can facilitate the formation of local clusters in the microstructure. Therefore, they can create possible crack nucleation sites under the stress leading to premature failure when the stress is applied [21].

In terms of the fracture toughness, by the increase in the amount of the reinforcements added in the matrix, fracture toughness and energy were changed modestly. One of the reasons is asserted that micro voids 
generation can occur in the interface of recycled rubbers and epoxy during the hot compaction. In particular, different contractions of rubber and epoxy during the solidification can bring some inequalities in the internal stress balance. This results in stress transfer reduction from epoxy to the recycled rubbers. Thus, a drop in the overall rigidity is observed on the compounds. As a conclusion, this kind of discontinuities in the rubber matrix shade the positive effects of reinforcements and the change in $K_{I c}$ and $G_{I c}$ can be considered as negligible.

Following 3PB, to better understand the toughening mechanisms of these composites, SEM observations were performed. First, in Figure 3 it is noted that brittle fracture surface is observed for SAG I. Rough fracture surface is generally an indicator of the crack deflection by many crack surfaces formation. Thus, if a crack comes across a robust reinforcement during its propagation, it finds alternative paths to maintain its propagation. As a consequence, a wavy crack propagation line is observed as shown with red arrows in Figure 3. Either, these hard particles may stop definitely the propagation of the crack as seen inside the red circle and this phenomenon is called as crack pinning [22, 23]. These mechanisms serve to obtain a tougher composite.

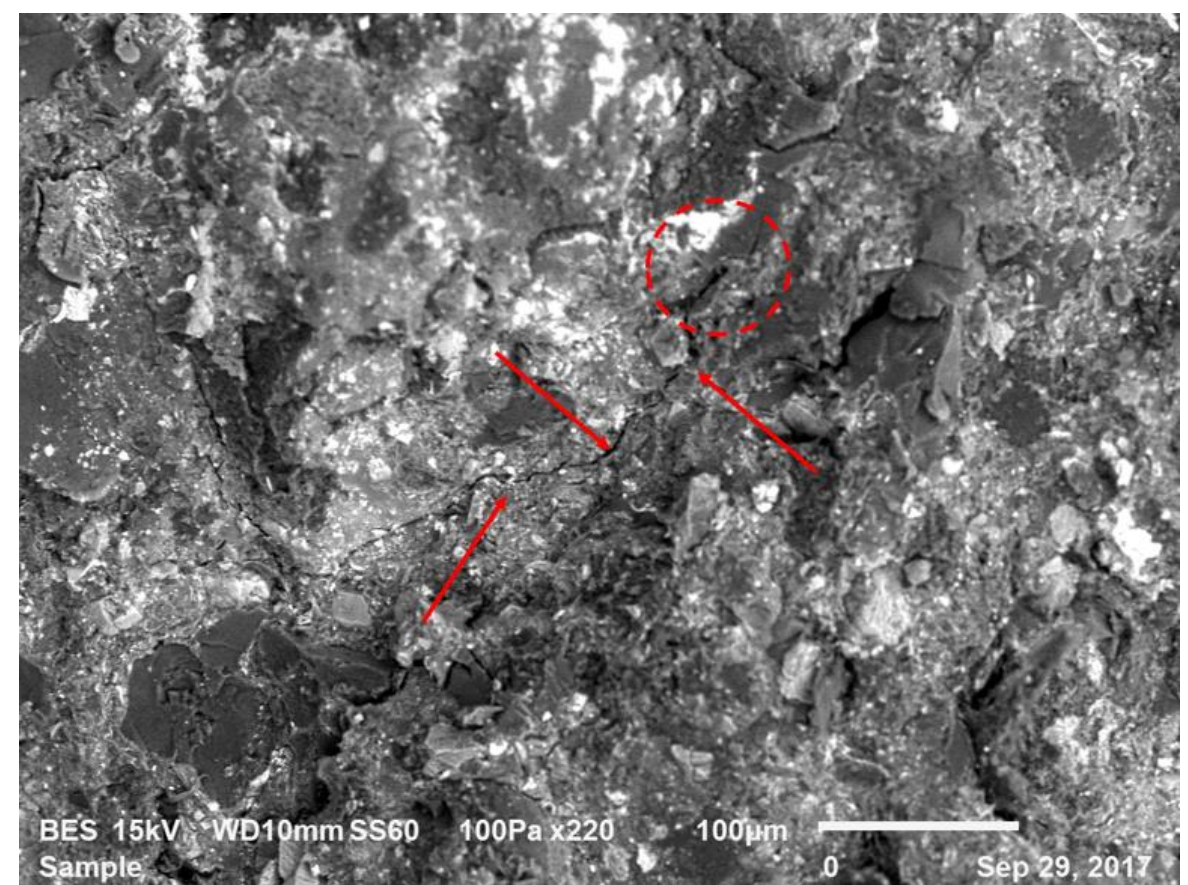

Figure 3. Micro crack formation in the crack surfaces and crack pinning mechanism

In Figure 4, another toughening mechanism called as shear band formation is observed in the fracture surface of SAG III group composites. In case of ductile fracture, shear band formation can improve the strength of the polymer [24]. Even though the final composite indicates a brittle fracture, crack propagation includes a localized viscoelastic and plastic energy dissipating process around the crack tip because of the polymer matrix. As a result, energy absorption is promoted by this mechanism in the material and it enhances the material's fracture toughness [25]. 


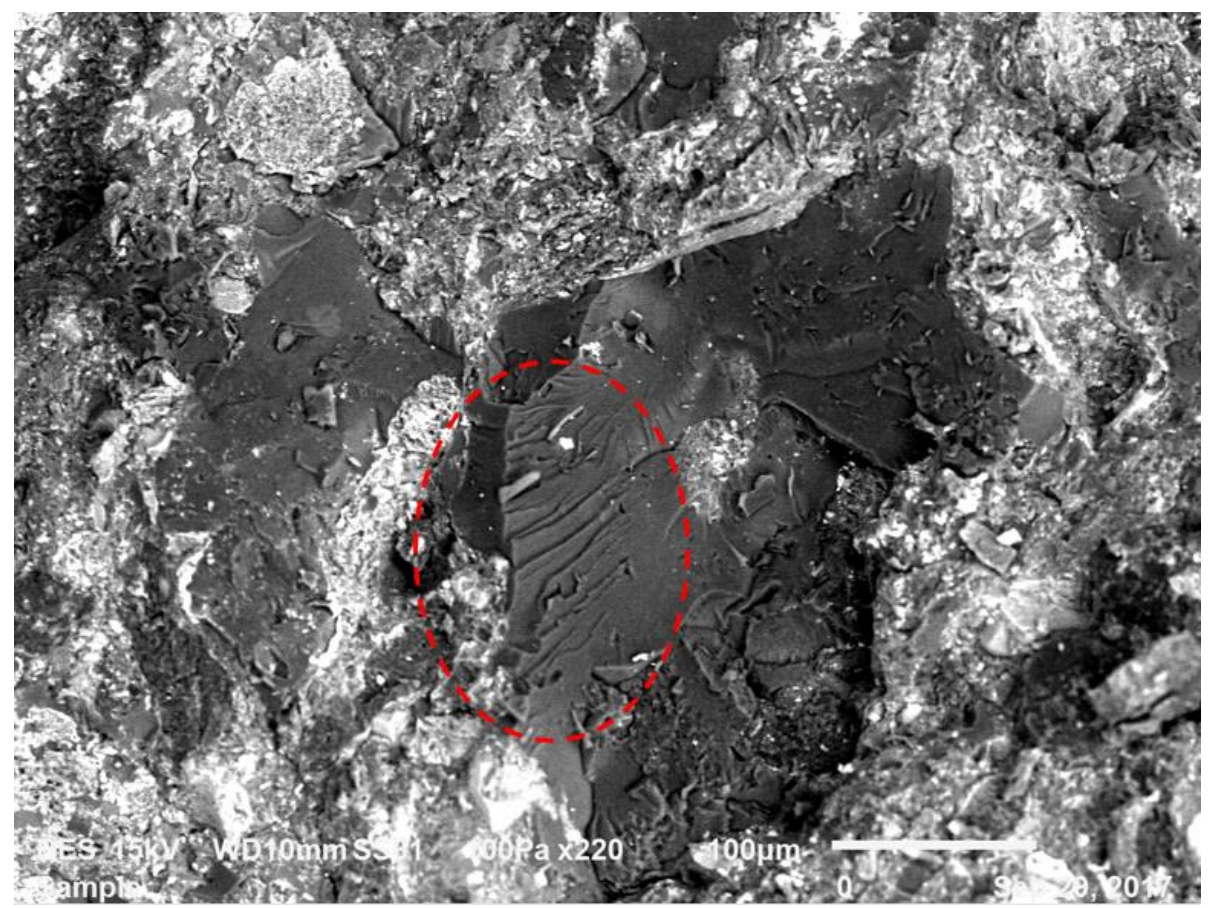

Figure 4. Shear band formation on crack surfaces of SAG III group composite

Lastly, in Figure 5a-b rubber tearing and cavitation are observed on the fracture surfaces of SAG II group composite, respectively. If the particle in front of the crack propagation has a soft nature like rubbers, it is torn by the crack as shown in Figure 5a producing cavitation on the fracture surfaces. This is again considered as a toughening mechanism and dissipates energy during fracture. To sum up, cavitation occurs generally in high local strain rates whereas shear driven mechanisms are observed in small strains. In low level of loading, shear bands blunt the crack, and crack tip acts as it is larger than it actually is. Thus, fracture toughness increases [26].

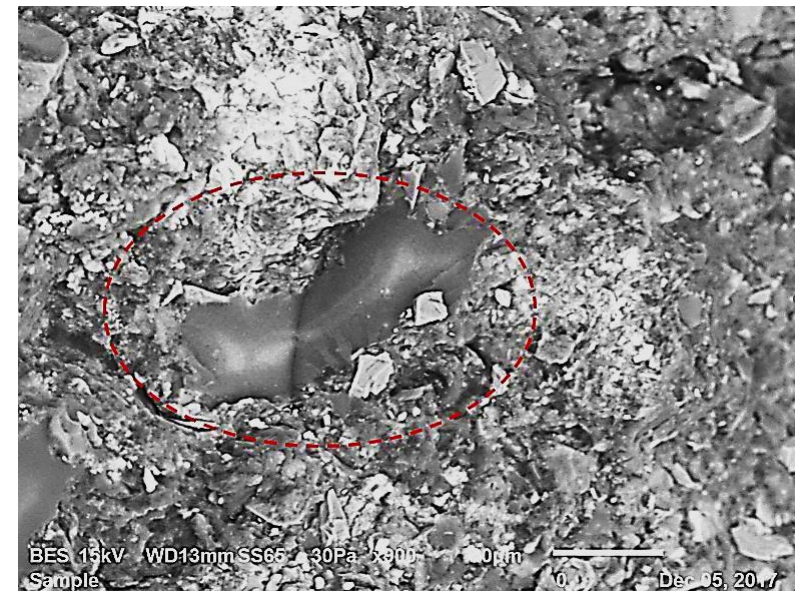

a)

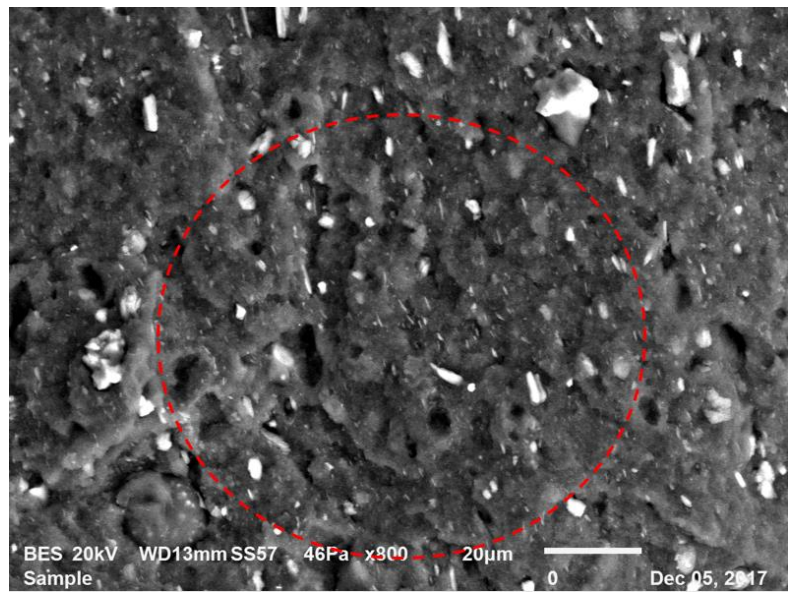

b)

Figure 5. a) Rubber tearing and b) cavitation in the fracture surfaces of SAG group composites

Cavitation can also be generated by shear deformation mechanisms. Larger Poisson's ratio of rubber induces greater transverse contraction of rubber particles. Therefore, rubber phase contracts more than epoxy phase during the cooling to the room temperature. These unbalanced contractions lead to the free volume expansion in the interface zone of epoxy and rubber. Accordingly, in the transition zones from rubbers to epoxy, rubber particles cavitation occurs. Even though the cavitation of rubber is not the only factor responsible for the high energy consumption, it takes an active role in epoxy toughening since plane strain constraint in front of the crack tip is relieved by this mechanism. Thus, a large scale shear deformation of the matrix is activated by the stress concentration along the cavitated particles [27-30]. 
As the last part of the mechanical characterization, to examine the energy absorption capacity of the SAG group composites, Charpy tests were performed. After obtaining absorbed energy values from the test device, values were divided to impacted section to make a reliable comparison. Results are given in Figure 6.

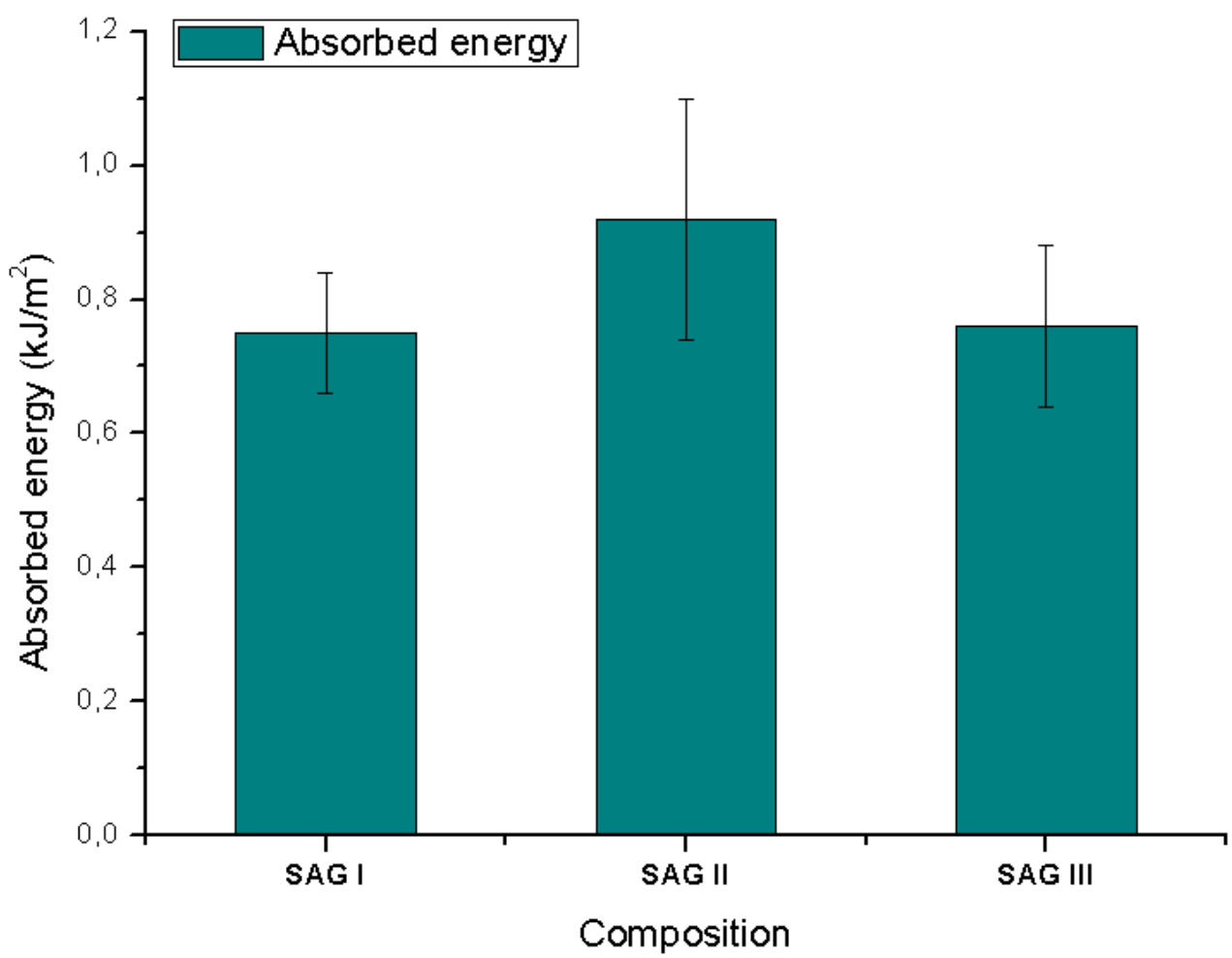

Figure 6. Absorbed energy during Charpy impact tests for SAG group composites

Charpy impact tests showed that excessive amount of the reinforcements has negative effects on energy absorbance capacity of the rubber-based composites. These reinforcements fell short of enhancing the composites' impact resistance. High deviations in the absorbed energy values are thought to be a consequence of the local heterogeneities in the microstructure [31]. In addition, high shear stresses in the interface of rubber and epoxy can be generated. For this reason, fracture occurs only along the main crack propagation line in the absence of interfacial cracks between epoxy and the rubber. Besides, pull out or debonding of the alumina and nano silica particles can be the reason for premature failure because of the decreased interface quality [32]. Hence, it is thought that any improvement in the interface quality between epoxy and rubbers can promote higher absorbed energy in these composites.

\subsection{Macro Scratch Tests}

Surface damages after macro scratch tests, are shown in the Figure 7. In Figure 7, the topography of the damage zone indicates a reasonable trend between 50k and 100k damage cycle. By the increasing number of the cycles, the damage zone expands in the horizontal direction. 

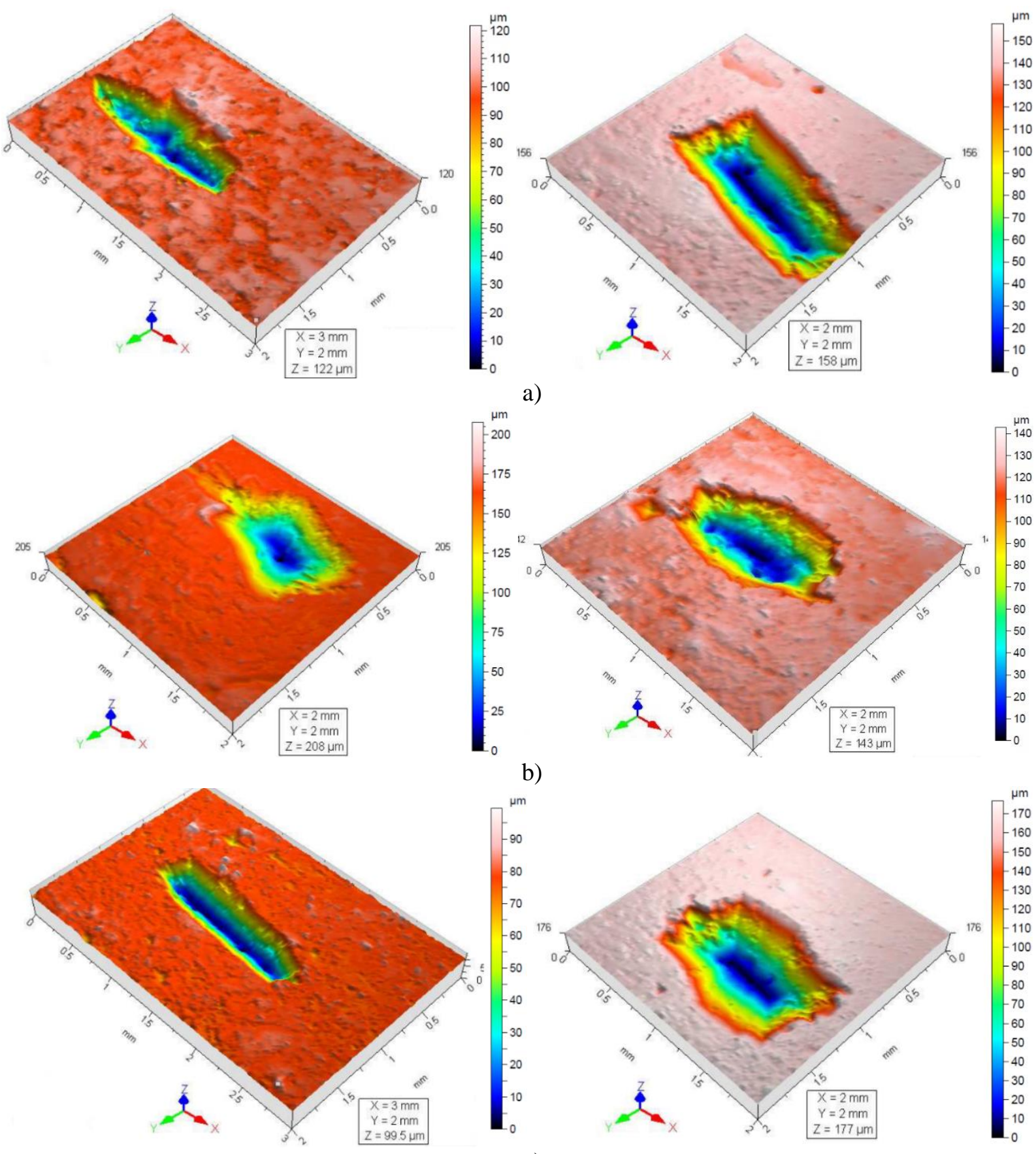

b)

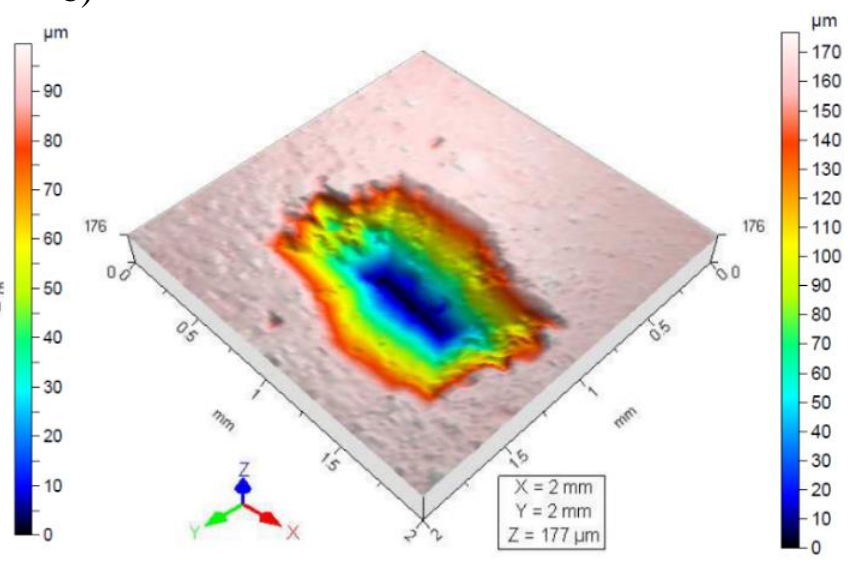

c)

Figure 7. 3D damage examination for 50 - 100k cycles a) SAG-I b) SAG-II c) SAG_III

After macro scratch testing, the surface and volume of the damage trace are given which were obtained by an optical profilometer. From Figure 8, it is seen that increasing amount of the robust fillers brings a more wear resistant composite. This situation is generally proportional to the surface hardness which is given in Table 3. Also, major part of the tests has indicated that after a certain period of time such as $50 \times 10^{3}$ cycles, the rate in the surface degradation is decreasing for various causes. For instance, the incorporation of the nano silica and GnPs can have an efficient role at high number of cycles as lubrication effect. Therefore, damage rate drops and it is not observed a significant difference between two damage cycles [33]. 


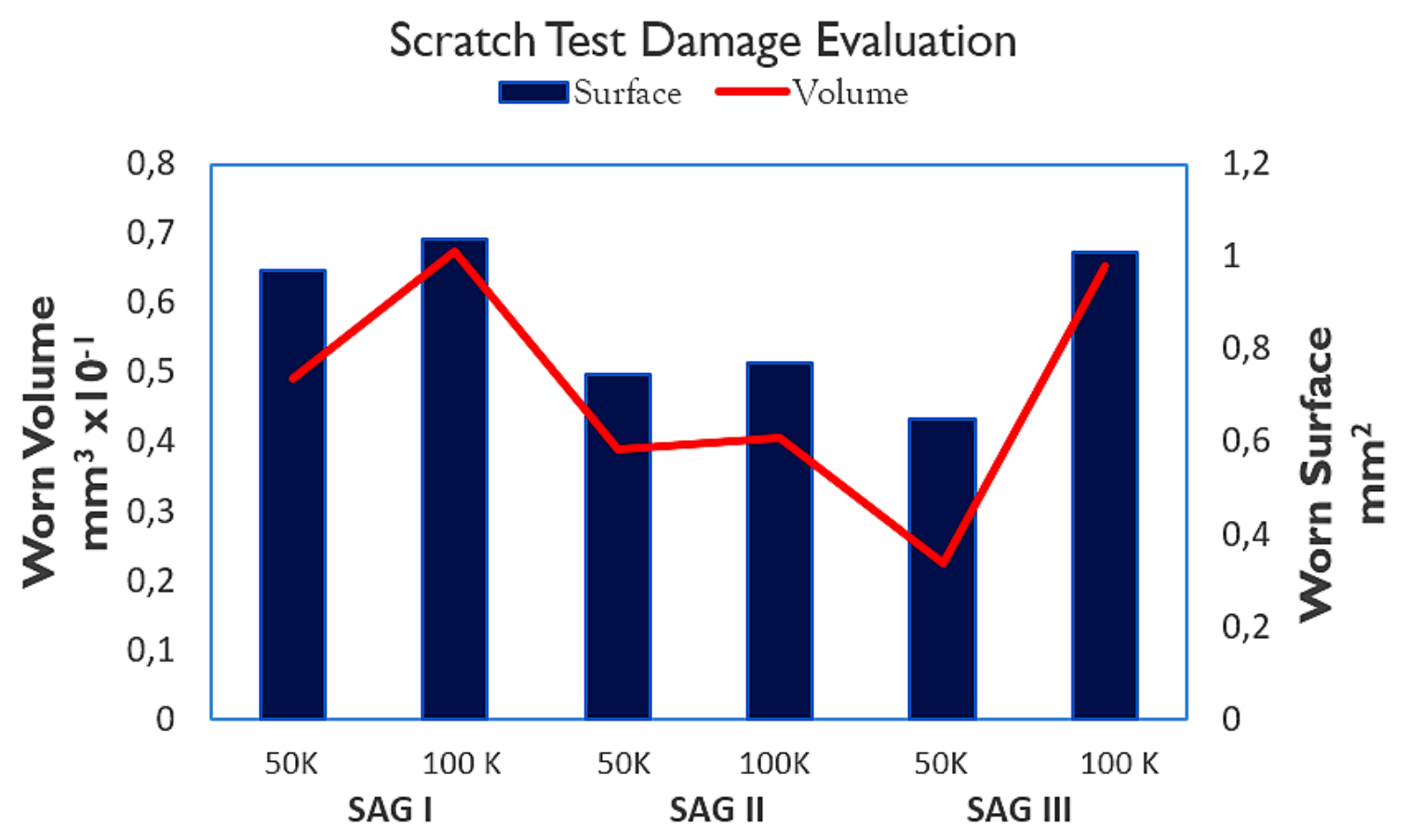

Figure 8. Damaged surface and volume on SAG I - II - III for 50 - 100k cycles

In fact, the main cause of damage could be the high interfacial shear stress between the matrix and the inclusions. Also, tangential surface stresses created behind the indenter brings more damage on the scratched surface [34].

\section{CONCLUSION}

Introduction of a cost-efficient approach to the rubber recycling problem constituted the main motivation of this study. By using recycled rubbers in the novel composite manufacturing, the environmental impact of scrap rubber was targeted to be reduced. During the manufacture step of the composites, recycled rubbers were blended with epoxy resin and silica, various contents of graphene nanoplatelets and $\gamma$-alumina were incorporated to this blend to reinforce the resulting composites. Positive outcomes of the surface activation were experienced compared to our former studies. After the manufacturing step, physical characteristics and mechanical properties were investigated by implementing a series of experimental methods. According to the results of $3 \mathrm{~PB}$ tests, favorable effects of reinforcements on elasticity modulus were observed. After that, a thorough evaluation of the composites' fracture toughness was carried out. Tests using SENB type specimens indicated some fluctuations in the fracture toughness. It is due to the formation of agglomerates under laboratory conditions in the microstructure with higher inclusion contents. These agglomerations should be eliminated by using high capacity ultrasound equipment and ball milling to have a more homogeneous mixture. Lastly, toughening mechanisms have been identified by SEM fractography. Crack deflection and crack pinning with the contribution of shear band formation have been observed as toughening mechanisms in these composites. In the end, macro wear tests showed that these composites protected their surface integrity after subjecting to recurring tribological loads. By comparing this study with authors' previous studies, it is evident that excessive amount of GnPs leads to decrease in the fracture toughness and strain at break. By considering all results, manufactured composites are promising candidates for diverse applications in automotive and aeronautics such as luggage weather strip and radiator linings.

\section{CONFLICTS OF INTEREST}

No conflict of interest was declared by the authors. 


\section{REFERENCES}

[1] May, C., Epoxy Resins: Chemistry and Technology 2 nd ed., CRC Press, London, 46-48, (2018).

[2] Branch, M., "Preparation of nano-scale $\alpha$-Al2O3 powder by the sol-gel method", Ceramics-Silikáty, 55: 378-383, (2011).

[3] Zhang, Z. and Lei, H., "Preparation of $\alpha$-alumina/polymethacrylic acid composite abrasive and its CMP performance on glass substrate", Microelectronic Engineering, 85: 714-720, (2008).

[4] Geim, A. K. and Novoselov, K. S., "The rise of graphene”, Nature Materials, 6: 183-191, (2007).

[5] Balandin, A. A., Ghosh, S., Bao, W., Calizo, I., Teweldebrhan, D., Miao, F., and Lau, C. N., "Superior thermal conductivity of single-layer graphene", Nano Letters, 8: 902-907, (2008).

[6] Scarpa, F., Adhikari, S. and Phani, A.S., "Effective elastic mechanical properties of single layer graphene sheets", Nanotechnology, 20(6): 65709, (2009).

[7] Wichmann, M.H.G., Schulte, K. and Wagner, H.D., "On nanocomposite toughness", Composites Science and Technology, 68: 329-331, (2008).

[8] Liang, Y.L. and Pearson, R.A., "Toughening mechanisms in epoxy-silica nanocomposites (ESNs)", Polymer, 50: 4895-4905, (2009).

[9] Srivastava, I. and Koratkar, N., "Fatigue and fracture toughness of epoxy nanocomposites", Journal of the Minerals, Metals and Materials Society, 62: 50-57, (2010).

[10] Nielsen, L. E. and Landel, R.F., Mechanical properties of polymers and composites 2 nd ed., CRC Press, New York, 118-120, (1994).

[11] Rothon, R., Particulate-filled polymer composites, iSmithers Rapra Publishing, Shawbury, 117-128, (2003).

[12] Rothon, R., "Mineral Fillers in Thermoplastics: Filler Manufacture and Characterisation", Mineral Fillers in Thermoplastics I, Springer, Berlin, Heidelberg, 67-107, (1999).

[13] Wetzel, B., Haupert, F. and Zhang, M.Q., "Epoxy nanocomposites with high mechanical and tribological performance", Composites Science and Technology, 63: 2055-2067, (2003).

[14] Irez, A. B., and Bayraktar, E., "Design of a Low-Cost Aircraft Structural Material Based on Epoxy: Recycled Rubber Composites Modified with Multifunctional Nano Particles", Mechanics of Composite and Multi-functional Materials, Volume 5 (pp. 73-80). Springer, Cham, (2020).

[15] Shokoohi, S., Arefazar, A. and Khosrokhavar, R., "Silane coupling agents in polymer-based reinforced composites: A review", Journal of Reinforced Plastics and Composites, 27: 473-485, (2008).

[16] Zhang, G., Wang, F., Dai, J. and Huang, Z., "Effect of functionalization of graphene nanoplatelets on the mechanical and thermal properties of silicone rubber composites", Materials, 9: 92, (2016).

[17] Dobrotă, D. and Dobrotă, G., "An innovative method in the regeneration of waste rubber and the sustainable development", Journal of Cleaner Production, 172: 3591-3599, (2018).

[18] Jacob, C. and De, S.K., "Powdered rubber waste in rubber compounds", Rubber Recycling, CRC Press, London, 213-246, (2005). 
[19] Jia, L. C., Li, Y. K. and Yan, D.X., "Flexible and efficient electromagnetic interference shielding materials from ground tire rubber", Carbon, 121: 267-273, (2017).

[20] Bilgili, E., Dybek, A., Arastoopour, H. and Bernstein, B., “A new recycling Technology: Compression Molding of Pulverized Rubber Waste in the Absence of Virgin Rubber", Journal of Elastomers \& Plastics, 35:235-256, (2003).

[21] Pathak, A.K., Borah, M., Gupta, A., Yokozeki, T. and Dhakate, SR., "Improved mechanical properties of carbon fiber/graphene oxide-epoxy hybrid composites", Composites Science and Technology, 135: 28-38, (2016).

[22] Zotti, A., Zuppolini, S., Zarrelli, M. and Borriello, A., "Fracture toughening mechanisms in epoxy adhesives", Adhesives-Applications and Properties, IntechOpen, Rijeka, Crotia, (2016).

[23] Kaynak, C., Sipahi-Saglam, E. and Akovali, G., "A fractographic study on toughening of epoxy resin using ground tyre rubber”, Polymer, 42: 4393-4399, (2001).

[24] Kinloch, A.J. and Young, R.J., "Fracture behavior of polymers", Springer Netherlands, Dordrecht, 31 32, (1995).

[25] Manjunatha, C.M., Taylor, A.C., Kinloch, A.J. and Sprenger, S., "The cyclic-fatigue behaviour of an epoxy polymer modified with micron-rubber and nano-silica particles", Journal of Materials Science, 44: 4487-4490, (2009).

[26] Irez, A. B., Bayraktar, E., and Miskioglu, I., "Flexural fatigue damage analyses of recycled rubbermodified epoxy- based composites reinforced with alumina fibres", Fatigue \& Fracture of Engineering Materials \& Structures, 42(4): 959-971, (2019).

[27] Yee, A.F. and Pearson R.A., "Toughening mechanisms in elastomer-modified epoxies", Journal of Materials Science, 21: 2462-2474, (1986).

[28] Zhang, J., Deng, S., Wang, Y. and Ye, L., "Role of rigid nanoparticles and CTBN rubber in the toughening of epoxies with different cross-linking densities", Composites Part A: Applied Science and Manufacturing, 80: 82-94, (2016).

[29] Zhou, W.Y., Qi, S.H., Zhao H.Z. and Liu, N.L., "Thermally conductive silicone rubber reinforced with boron nitride particle", Polymer Composites, 28: 23-28, (2007).

[30] Liang, Y.L. and Pearson, RA., "The toughening mechanism in hybrid epoxy-silica-rubber nanocomposites (HESRNs)”, Polymer, 51: 4880-4890, (2010).

[31] Pereira, A.C., Monteiro, S.N., De Assis, F.S., Margem, F.M., Da Luz, F.S. and De Oliviera Braga, F., "Charpy impact tenacity of epoxy matrix composites reinforced with aligned jute fibers", Journal of Materials Research and Technology, 6: 312-316, (2017).

[32] Ye, Y., Chen, H., Wu, J. and Ye, L., "High impact strength epoxy nanocomposites with natural nanotubes", Polymer, 48: 6426-6433, (2007).

[33] Irez, A.B., Bayraktar, E. and Miskioglu, I., "Recycled and devulcanized rubber modified epoxy-based composites reinforced with nano-magnetic iron oxide, Fe3O4", Composites Part B: Engineering, 148: $1-13,(2018)$.

[34] Zanchet, A., Carli, L. N., Giovanela, M., Brandalise, R. N., and Crespo, J. S., "Use of styrene butadiene rubber industrial waste devulcanized by microwave in rubber composites for automotive application", Materials \& Design, 39: 437-443, (2012). 